\title{
Operationalizing the telecoupling framework for migratory species using the spatial subsidies approach to examine ecosystem services provided by Mexican free-tailed bats
}

\author{
Laura López-Hoffman ${ }^{1,2}$, Jay Diffendorfer $^{3}$, Ruscena Wiederholt $^{4}$, Kenneth J. Bagstad $^{3}$, Wayne E. Thogmartin ${ }^{5}$, Gary McCracken $^{6}$, \\ Rodrigo L. Medellin ${ }^{7}$, Amy Russell $^{8}$ and Darius J. Semmens ${ }^{3}$
}

\begin{abstract}
Drivers of environmental change in one location can have profound effects on ecosystem services and human well-being in distant locations, often across international borders. The telecoupling provides a conceptual framework for describing these interactions - for example, locations can be defined as sending areas (sources of flows of ecosystem services, energy, or information) or receiving areas (recipients of flows). However, the ability to quantify feedbacks between ecosystem change in one area and societal benefits in other areas requires analytical approaches. We use spatial subsidies - an approach developed to measure the degree to which a migratory species' ability to provide services in one location depends on habitat in another location - as an example of how telecoupling can be operationalized. Using the cotton pest control and ecotourism services of Mexican free-tailed bats as an example, we determined that of the 16 states in the United States and Mexico where the species resides, three states (Texas, New Mexico, and Colorado) are receiving areas, while the rest of the states are sending areas. In addition, the magnitude of spatial subsidy can be used as an indicator of the degree to which different locations are telecoupled to other locations. In this example, the Mexican free-tailed bat ecosystem services to cotton production and ecotourism in Texas and New Mexico are heavily dependent on winter habitat in four states in central and southern Mexico. In sum, spatial subsidies can be used to operationalize the telecoupling conceptual framework by identifying sending and receiving areas, and by indicating the degree to which locations are telecoupled to other locations.
\end{abstract}

Key Words: ecosystem services; Mexican free-tailed bats; pest control; spatial subsidies; telecoupled natural-human systems; telecoupling; transborder conservation

\section{INTRODUCTION}

Within complex, coupled natural-human systems, the drivers of environmental change in one location can have profound effects on ecosystem services and human well-being in distant locations, often across international borders (López-Hoffman et al. 2009, 2010). International trade and information networks move vast quantities of matter, energy, and information that underpin global to local exchange of ecosystem services (Kissinger and Rees 2010, Kastner et al. 2011, 2014). Oceanic, atmospheric, and hydrological flows are further long-distance/international transporters of ecosystem services (Bagstad and Wiederholt 2013). The phenomena of long-distance cause-effect interactions in social-ecological systems (Brauman et al. 2007, DeFries et al. 2010, Kissinger and Rees 2010, Lenzen et al. 2012) is well recognized. Nonetheless, most studies to date have treated distal forces as exogenous variables, and have rarely considered the feedbacks between ecological processes in one location and ecosystem services and human well-being in other locations (Kissinger et al. 2011, Liu et al. 2013, 2016). The conceptual framework of telecoupling developed by Liu and colleagues (Liu et al. 2013, 2016) provides a way of articulating important features of long-distance interactions in social-ecological systems such as sending areas (sources of flows of ecosystem services, energy, or information), receiving areas (recipients of flows), or spillover areas (locations affecting and/or affected by interactions between sending and receiving systems). However, to fully develop and extend this conceptual framework requires the ability to identify and quantify telecouplings. To overcome this hurdle, we present operational tools to measure the flow and value of telecoupled ecosystem service benefits specifically related to the provision of ecosystem services by migratory species.

Migratory species move regularly between habitats to take advantage of seasonal resources. In North America, many bird and bat species spend the summer in breeding grounds in the northern latitudes of Canada and the United States and migrate south to the southern United States, Mexico, and Central America to spend the winter (López-Hoffman et al. 2017). As they move between habitats, these migratory species support ecosystem functions in multiple areas, thereby creating ecological "mobile links" between their distant habitats (Gilbert 1980, Lundberg and Moberg 2003). Further, as these animals travel, they often provide benefits to people, such as controlling crop pests, pollinating food plants, or supporting recreational hunting and viewing activities (Kunz et al. 2011, Wenny et al. 2011). Because the population viability of a migratory species depends on habitat in different locations, it follows that the ecosystem services provided by the species in one location depend upon habitat and ecological processes provided in other locations. This dependency creates a telecoupling such that impacts on the habitat of a migratory species in one location will affect the ecosystem services enjoyed by people in other locations (Hulina et al. 2017).

The spatial subsidies approach (Semmens et al. 2011, LópezHoffman et al. 2013) assesses the degree to which ecosystem service provision in one location depends on a migratory species' habitat in other locations. The approach is called "spatial

${ }^{1}$ School of Natural Resources and the Environment, ${ }^{2}$ Udall Center for Studies in Public Policy, University of Arizona, Tucson, AZ, USA, ${ }^{3}$ United States Geological Survey, Geosciences and Environmental Change Science Center, Denver, CO, USA, ${ }^{4}$ Everglades Foundation, Palmetto Bay, FL, ${ }^{5}$ United States Geological Survey, Upper Midwest Environmental Sciences Center, La Crosse, WI, USA, ${ }^{6}$ Department of Ecology and Evolutionary Biology, University of Tennessee, Knoxville, TN, USA, ${ }^{7}$ Instituto de Ecología, Universidad Nacional Autónoma de México, México, ${ }^{8}$ Department of Biology, Grand Valley State University, Allendale, Michigan, USA 
subsidies" because species often provide more ecosystem service benefits in certain parts of their range than in others, while habitats in other parts of the range are often more critical to a species' population viability. In such situations, people in areas where the species provides the most ecosystem service benefits may in effect be "subsidized" by the habitat conservation efforts of people in the areas of most critical habitat (Semmens et al. 2011, López-Hoffman et al. 2013). The spatial subsidies approach operationalizes the telecoupling framework by identifying areas that are sending and receiving subsidies of ecosystem services.

We provide an example of how the telecoupling framework can be operationalized by presenting spatial subsidy calculations for the Mexican free-tailed bat (Tadarida brasiliensis mexicana). Both male and female bats winter in southern Mexico, and in the summer, females travel to roosts in the southwestern United States and northern Mexico to birth their pups. The species is insectivorous and preys on bollworms (Helicoverpa zea), the most common and damaging pest to cotton production in Texas and across the southwestern United States (Cleveland et al. 2006, Federico et al. 2008). By reducing crop damage from bollworms, Mexican free-tailed bats provide an economic benefit to agricultural producers. We have estimated that the bats provided an annual average of US\$12.4 million in pest control services in cotton fields across the U.S. southwest from 1990 to 2008 (LópezHoffman et al. 2014). In addition, the viewing of the bats' evening emergences from their roosts has become a highly popular activity for more than 240,000 people per year, which generates more than US\$6.5 million per year in economic benefits (Bagstad and Wiederholt 2013).

The spatial subsidy estimates we present indicate which states in the United States and Mexico either send subsidies to, or receive subsidies from, other states. The estimates also suggest the degree to which different portions of the Mexican free-tailed bat range subsidize ecosystem services in other locations, and as such the degree to which different locations are telecoupled to other locations. Nonetheless, our goal is not to promote these estimates as precise monetary figures. Rather, we aim to provide operational tools to measure the flow and value of telecoupled ecosystem service benefits.

\section{METHODS}

The purpose of the spatial subsidies approach is to identify the locations that (a) send subsidies by contributing to the overall viability of migratory species that in turn provide services to humans throughout their entire range, and (b) receive subsidies in the form of services provided locally by migratory populations that are dependent upon habitat elsewhere. Two types of information are required to estimate spatial subsidies: the first is information about the quantity of ecosystem services provided by a migratory species and the locations where people most benefit from those services; the second is information about the proportional dependence of the migratory species' population viability on different portions of its range. In this section, we first review the equation to calculate spatial subsidies, then detail the data we used to parameterize the quantity and location of Mexican free-tailed bat ecosystem services, and finally we explain the approach we used to estimate proportional dependence.

\section{Spatial subsidies calculation}

The determination of whether a given location is sending or receiving a subsidy depends on the balance between the services received from other locations and the habitat support the area provides to the species (Semmens et al. 2011). For a single species, the net difference between sent contribution and received benefit is the spatial subsidy for location $A\left(Y_{A}\right)$ :

$$
Y_{A}=V_{S} \times D_{S A}-V_{S A}
$$

where $V_{S}$ is the total value of migratory services provided by a species $S$ throughout its range, $V_{S A}$ is the value of services provided by species $S$ at location $A$, and $D_{S A}$ is the proportional dependence of the species' population on location $A$. $D_{S A}$ for a given location cannot be greater than one, and the total of all $D_{S}$ values must sum to one across all locations. The latter unit-sum constraint assumes migratory species are dependent upon favorable habitat across their entire range; they cannot be more or less than $100 \%$ dependent upon their environment.

The values calculated in Eq. 1 are based on the recurring, annual value of services provided by the migratory species. The first term, $V_{S} \times D_{S A}$, represents how much a particular location contributes to the overall ecosystem service value. Subtracting the last term, $V_{S A}$, from the equation yields the net subsidy. Positive values indicate location $A$ is sending subsidies to other areas. Negative values indicate location $A$ is receiving subsidies from other areas. When applied to all sending and receiving locations throughout a species' range, Eq. 1 satisfies the requirement that the rangewide sum of all subsidies is zero.

\section{Parameterizing ecosystem service values}

We used our previous work to value the cotton pest control services (López-Hoffman et al. 2014) and ecotourism services (Bagstad et al. 2013) of Mexican free-tailed bats to parameterize our estimates of the quantity and location of the ecosystem services provided by this species. Values are expressed in $2011 \mathrm{U}$. S. dollars. We briefly summarize the methods of the previous valuation studies and the results.

\section{Parameterizing bat pest control}

We parameterized $V_{S A}$ values for pest control using data from López-Hoffman et al. (2014), an avoided-cost assessment of the value of reduced crop damage and reduced insecticide use resulting from the foraging of Mexican free-tailed bats on bollworm pests. This approach consisted of (a) estimating the number of insect pests preyed upon nightly by individual bats, (b) determining the hectares of cotton fields within a given distance of known bat roosts, and then (c) estimating the value of the crops that would have been damaged in the absence of bats (Cleveland et al. 2006, Wiederholt et al. 2015).

Cleveland et al. (2006) first applied an avoided-cost approach to valuing Mexican free-tailed bat pest control services to cotton in the eight-county Texas Winter Garden region. In López-Hoffman et al. (2014), we refined the approach and expanded the geographic extent of analysis. The refinements consisted of (a) estimating both the reduced private costs (i.e., to farmers) and the reduced public (i.e., societal) costs of insecticides released into the environment; (b) considering how the adoption and expansion of transgenic Bacillus thuringiensis (Bt) cotton, starting in 1996, subsequently affected service values; (c) using improved estimates 
Table 1. Spatial subsidy calculations for the Mexican free-tailed bats summed by state. Note that several states have more than one bat breeding roost. Currency is expressed in 2011 U.S. dollars.

\begin{tabular}{|c|c|c|c|c|c|c|c|}
\hline Country & State & Season & $V_{S}^{\dagger} \operatorname{cotton} \$$ & $V_{S}$ viewing \$ & $V_{S}$ total $\$$ & $D_{s}^{\dagger}$ & Total subsidy $\$$ \\
\hline U.S. & Arizona & Summer & 5,000 & 9,000 & 14,000 & 0.0060 & 103,166 \\
\hline U.S. & California & Summer & 56,000 & 58,000 & 114,000 & 0.0063 & 7,614 \\
\hline U.S. & Colorado & Summer & 0 & 83,000 & 83,000 & 0.0020 & $-44,131$ \\
\hline U.S. & New Mexico & Summer & 28,000 & $3,477,000$ & $3,505,000$ & 0.0069 & $-3,371,658$ \\
\hline U.S. & Oklahoma & Summer & 497,000 & 30,000 & 527,000 & 0.0341 & 133,193 \\
\hline U.S. & Texas & Summer & $11,652,000$ & $2,840,000$ & $14,492,000$ & 0.2927 & $-8,821,430$ \\
\hline Mexico & Coahuila & Summer & 222,000 & 0 & 222,000 & 0.0380 & 514,120 \\
\hline Mexico & Nuevo Leon & Summer & 0 & 0 & 0 & 0.0498 & 965,244 \\
\hline Mexico & Sinaloa & Summer & 36,000 & 0 & 36,000 & 0.0020 & 2,873 \\
\hline Mexico & Sonora & Summer & 0 & 0 & 0 & 0.0418 & 810,750 \\
\hline Mexico & Tamaulipas & Summer & 382,000 & 0 & 382,000 & 0.0204 & 12,759 \\
\hline Mexico & Chiapas & Winter & 0 & 0 & 0 & 0.0900 & $1,744,148$ \\
\hline Mexico & Hildago & Winter & 0 & 0 & 0 & 0.0900 & $1,743,535$ \\
\hline Mexico & Michoacan \& Jalisco & Winter & 0 & 0 & 0 & 0.1876 & $3,633,797$ \\
\hline Mexico & Queretaro & Winter & 0 & 0 & 0 & 0.1324 & $2,566,021$ \\
\hline Totals & & & $12,878,000$ & $6,497,000$ & $19,375,000$ & 1.0000 & 0 \\
\hline
\end{tabular}

${ }^{\dagger} V_{S}$ is the total value of migratory services provided by a species $\mathrm{S}$ throughout its range.

${ }^{\ddagger} D_{S}{ }_{S}$ is proportional dependence.

of societal costs by considering only insecticides specifically targeted to cotton bollworms (Leach and Mumford 2008); and (d) expanding the analysis of pest control values to all cottonproducing areas within $50 \mathrm{~km}$ of major bat roosts across the southwestern United States and northern Mexico rather than just the Texas Winter Garden region.

We used the annual estimates of pest control values from 1990 to 2008 in López-Hoffman et al. (2014) to determine a mean annual value over that time period for each state where Mexican freetailed bats are located. Pest control values were spatially variable, which reflected county-level differences in bat population size, area of cotton planted, type of cotton, and year of adoption of Bt cotton (see López-Hoffman et al. 2014 for further explanation). Estimates of the mean county-level ecosystem service value varied widely from $\$ 0.01$ to $\$ 8.06$ per hectare; the highest values $(>\$ 2.60$ per hectare) were all found in Texas (Table 1).

\section{Parameterizing bat ecotourism}

We parameterized $V_{S A}$ values for ecotourism using data about consumer surplus from Bagstad and Wiederholt (2013), a study of visitation rates and consumer surplus for recreational visitors to viewing sites for the Mexican free-tailed bat throughout the southwestern United States. Consumer surplus is the difference between the maximum price a consumer is willing to pay for something and the actual price they do pay, which is a measure of the net benefits received by the consumer. Recreational viewing of Mexican free-tailed bats occurs in six states in the United States. The most significant economic benefits from bat viewing occur in New Mexico (at Carlsbad Caverns National Park), which generates more than US\$3.5 million per year in economic benefits, followed by Texas (primarily at the Congress Avenue Bridge in Austin and Bracken Cave near San Antonio), with about US\$2.8 million per year in benefits (Table 1). Although bat viewing occurs at some sites in Mexico, visitation data for those sites either do not exist or were not obtainable for this study (Rodrigo Medellín, personal observation).

\section{Estimating proportional dependence}

To estimate $D_{S A}$, the proportional dependence of Mexican freetailed bats on different roosts and habitat regions, we used a network model for the species that was developed by Wiederholt et al. (2013). The model simulates bat migration between four winter regions in southern Mexico and 25 major summer breeding roosts in northern Mexico and the southwestern United States, with each site receiving individuals from several locations (Fig. 1). Expected migratory routes are determined based on distancebased formulations of migration costs. The approach allows us to simulate changes in migratory population size associated with the loss of any particular habitat region or roost (Wiederholt et al. 2013, 2015).

To determine the proportional dependence on each habitat area, we simulated a habitat removal experiment-removing each habitat (i.e., each summer roost and winter region) with replacement from the network model. In line with other analyses of migratory populations (Taylor and Norris 2010, Rayfield et al. 2011), we quantified the impact of each area's removal on the total summer population size. When removing a given summer roost or winter region from the model, the individuals contained in that location were allowed to migrate to other areas. This approach was used by Wiederholt et al. (2015) to determine the relative importance of the various breeding roosts for conservation activities.

We rescaled the results of the habitat removal experiment to apportion $50 \%$ of the proportional habitat dependency, $D_{S}$, to the winter habitats, and $50 \%$ to the summer breeding habitats. This was necessary to reflect the fact that each habitat type is equally important for population viability. Winter sites are critical because that is where mating occurs and where most males reside year-round, whereas summer sites are critical for the birthing and rearing of juveniles. 
Fig. 1. Summer breeding roost sites (dots 1-25) and wintering regions (dots 26-29) for the Mexican free-tailed bat (Tadarida brasiliensis mexicana). Line colors represent the total number of migrant bats. If a summer site was connected to more than one route, the circle representing the summer site was filled and outlined with the colors of the two different routes (from Wiederholt et al. [2013]).

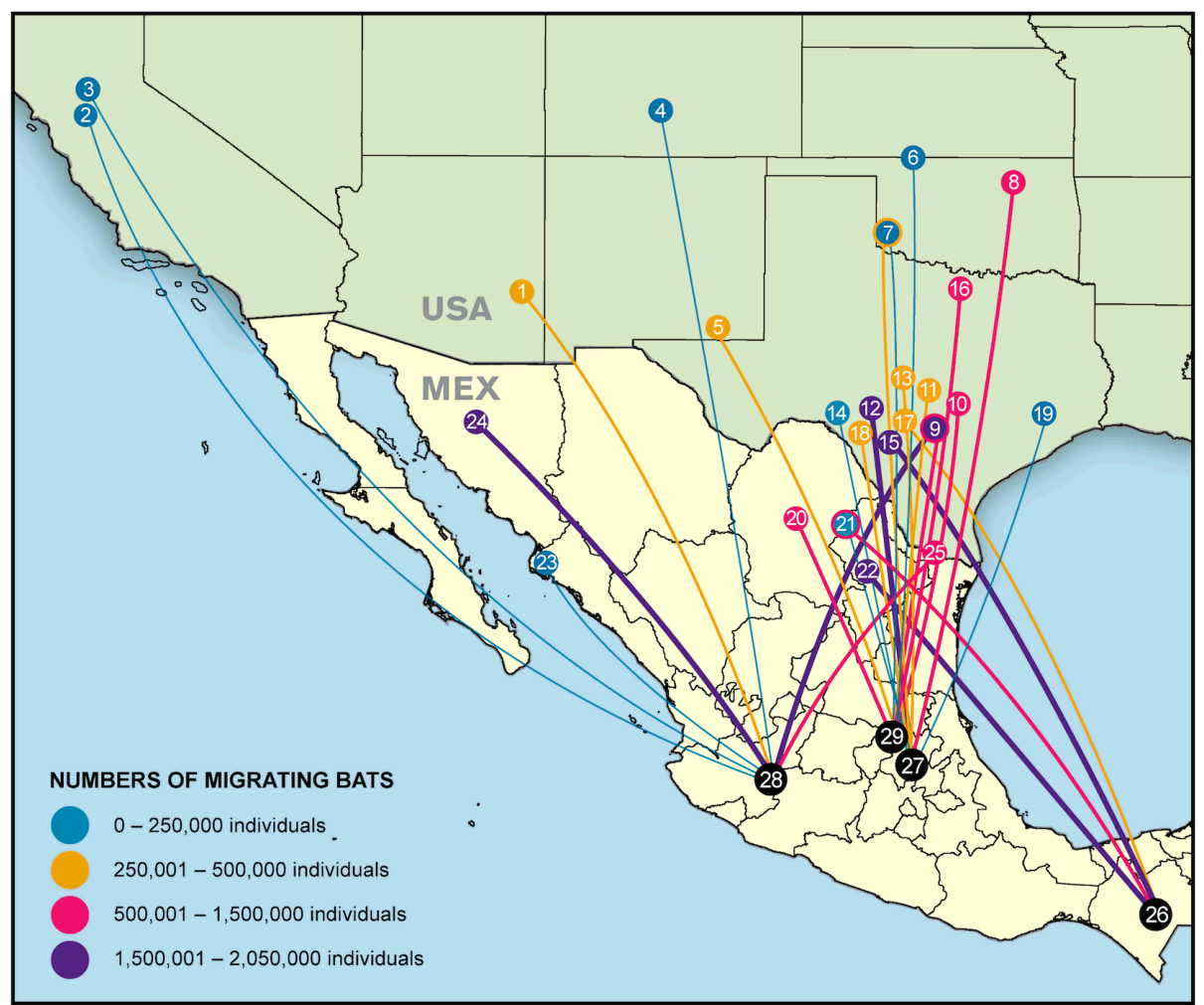

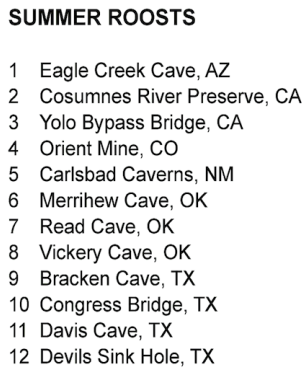

WINTER SUBREGIONS

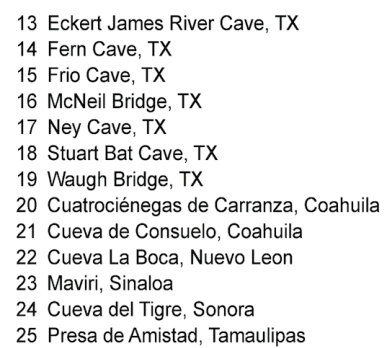

25 Presa de Amistad, Tamaulipas

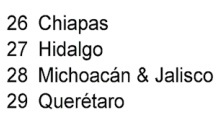


Fig. 2. Results of the habitat removal experiment. Changes in summer population size with eliminated habitat (each breeding roost site and winter region) are expressed as the proportional difference from the baseline summer population size (i.e., the summer population with no removals).

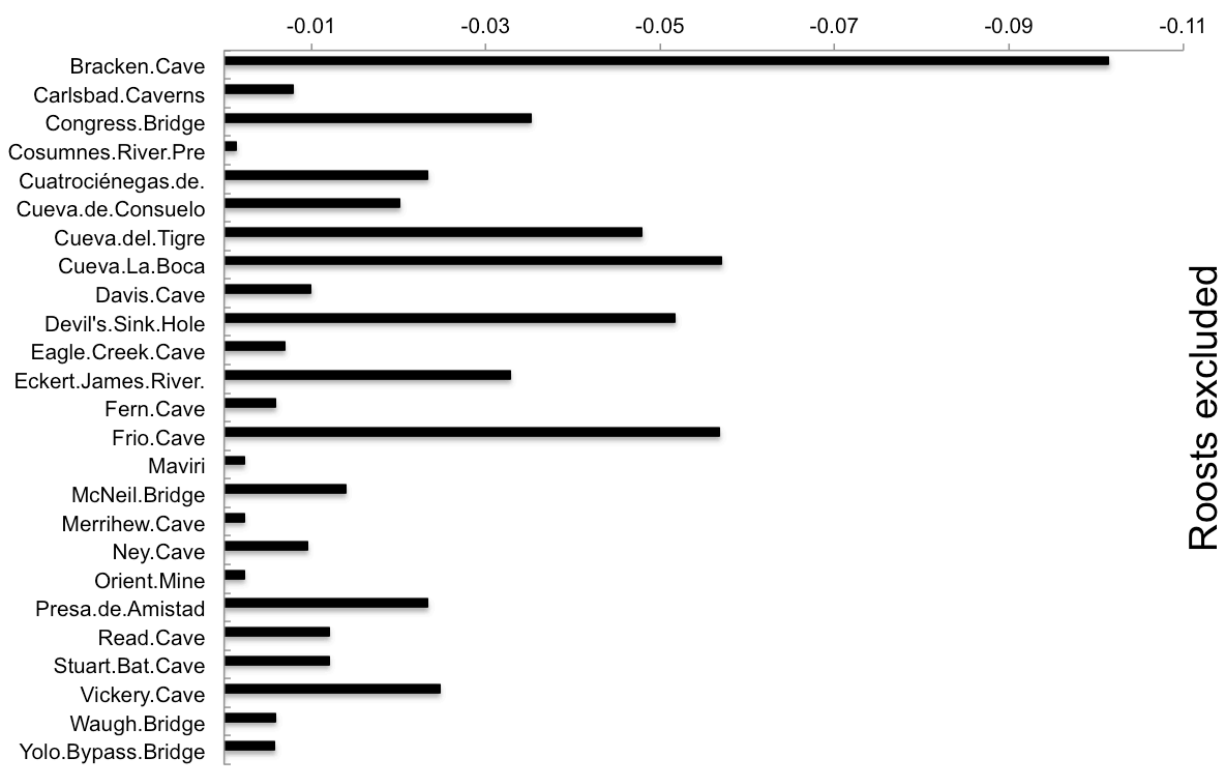

Deviation from baseline summer population size

U.S. and Mexican states had positive spatial subsidy values, which indicates that they are sending subsidies to other locations. To use the language of the telecoupling framework (Liu et al. 2013), Texas, New Mexico, and Colorado are receiving locations in the telecoupled natural-human system of Mexican free-tailed bats and their ecotourism and cotton pest control services, while the other states are sending locations.

Of the three receiving locations (locations with calculated negative spatial subsidy values), Texas and New Mexico had the most negative values, approximately -US\$8.8 million and -US\$3.4 million, respectively. In contrast, Colorado, another receiving region, had a less negative subsidy value (approximately US\$44,000). The sending locations with the greatest positive subsidy values were, in descending order, the Mexican states of Michoacán and Jalisco (US\$3.6 million combined), Queretaro (US\$2.6 million), and Chiapas and Hidalgo (US\$1.7 million each). The Mexican state of Sinaloa had the lowest positive subsidy value of any sending location, at approximately US\$3000.

\section{DISCUSSION}

Operationalizing the telecoupling framework

We used spatial subsidies to operationalize key concepts from the telecoupling framework (Liu et al. 2013) by identifying locations that receive and send flows of ecosystem services. In our analysis of telecoupling for the Mexican free-tailed bat, three statesTexas, New Mexico, and Colorado - have negative spatial subsidy values, and as such are receiving areas. All the other U.S and Mexican states have positive subsidy values, and therefore are sending areas.
Spatial subsidies can also extend the analysis of telecoupled systems by evaluating the degree to which different locations are coupled to other locations. The magnitude of a negative spatial subsidy value can be interpreted to indicate the degree to which a location depends upon habitat in other locations for the provision of ecosystem services locally. Of the three locations with negative subsidy values, Texas and New Mexico had the most negative values. On the other hand, the magnitude of a positive subsidy value can indicate whether a location enables the provisioning of ecosystem services in other locations by providing critical habitat for migratory species. In this case, we see a pattern of the benefits from Mexican free-tailed bat ecosystem services to cotton production and ecotourism in Texas and New Mexico being heavily dependent on winter habitat in four states in central and southern Mexico.

Important caveats to the subsidy calculations presented

There are a number of important caveats to consider. First, the spatial subsidy estimates are a static snapshot of a dynamic system. Ecosystem service values can change over time due to both ecological and socioeconomic factors (Eigenbrod et al. 2009, 2011, Koch et al. 2009, Burkhard et al. 2011, Barbier 2012, Johnson et al. 2012, Lautenbach et al. 2012, Yuan et al. 2012, López-Hoffman et al. 2014). For example, in our previous work, we have shown that the value of bat pest control services in cotton was largely influenced by temporal changes in cotton commodity price, impacts of demand and price changes on the number of hectares planted with cotton, and the technological substitution of Bt transgenic cotton for non-Bt cotton (López-Hoffman et al. 2014). 
Second, the spatial subsidy calculations do not fully account for all the ways that Mexican free-tailed bats may be providing benefits to society. Critics have long pointed out that it is impossible to identify and measure, let alone value, all the ways functioning ecosystems provide benefits to society (Spash 2008, Peterson et al. 2010, Muradian and Rival 2012). It is important to note that in the present analysis, we used two types of ecosystem services - pest control services to cotton, and ecotourism - that happen to be most commonly enjoyed in the United States. However, Mexican free-tailed bats are generalist predators (Lee and McCracken 2005, McCracken et al. 2012) and likely provide significant pest control services to other crops, in particular corn and tomatoes. Unlike cotton, corn and tomato production is common in Mexico. At present, there are insufficient data to assess the species' pest control services to these crops, as well as any other regulating and cultural services provided by bats. Nonetheless, had the necessary data been available to assess additional ecosystem service values, the spatial subsidy calculations might have been very different: locations in Mexico might have been sending less subsidy to the United States, or perhaps might have been receiving locations.

Finally, our analysis does not consider the three types of uncertainty in our calculations: observation (measurement) error, parametric uncertainty, and external stochasticity (environmental and demographic stochasticity). In future work, we will employ several techniques to address these types of uncertainty, including using parameter ranges for maximum and minimum estimates of service values and proportional dependencies to generate confidence intervals, and varying input parameters such as bat survival and mortality to identify the system's sensitivity to key factors.

Applications of spatial subsidies to the governance of telecoupled natural-human systems

Our results emphasize the necessity of coordinated binational conservation efforts for maintaining habitat across the Mexican free-tailed bat's range, as well as efforts to protect critical habitat areas in the United States and Mexico. Results from the spatial subsidies approach could be used to more effectively target conservation funding to priority areas. In addition, they could be used as an argument for long-term population-level monitoring, as bats may switch roosts over time, and the population's viability depends on habitat in both countries (Glass 1982, Genoways et al. 2000, McCracken 2003). North America lacks a formal treaty that protects migratory bats. However, data such as ours that elucidate the cross-border connections between people and locations that receive benefits in one country and those that provide benefits in another country might prove useful for the establishment of such an agreement. Despite the lack of a formal treaty, other North American conservation agreements do exist, such as the Program for the Conservation of Migratory Bats (between the United States and Mexico) and the North American Bat Conservation Partnership (among Canada, the United States, and Mexico) (Keeley et al. 2003, Medellin 2003).

The notion that distant locations in telecoupled systems may be critical to enabling people to benefit from ecosystem services locally addresses a central goal of political ecology: to reveal winners and losers and hidden costs in environmental outcomes (Robbins 2011). In our study, we see a pattern of the benefits from
Mexican free-tailed bat ecosystem services in the southwestern United States being largely subsidized by overwintering habitat in central and southern Mexico. In other words, the costs of enabling bat ecosystem services in the southwestern United States are born by habitat and the habitat conservation efforts of people in central and southern Mexico. Elsewhere, we have suggested that the spatial subsidies concept could be used to structure crossjurisdictional payments for ecosystem services (PES) programs (Semmens et al. 2011, López-Hoffman et al. 2013). For example, our results could be used to argue for U.S. agricultural payment programs to support landowners in Mexico for bat habitat conservation efforts. However, the wise implementation of new ideas such as PES that arise from the ecological and natural resources sciences requires caution and prudence.

\section{CONCLUSIONS}

The goal of the telecoupling conceptual framework is to stimulate research that elucidates, measures, and ultimately enables society to govern long-distance cause-effect relationships in socialecological systems. However, to fully implement the conceptual framework requires the ability to quantify the degree of telecoupling between locations. We have used spatial subsidies, which measure the degree to which a migratory species' ability to provide services in one location depends on habitat in another location, as an example of how the telecoupling framework can be operationalized. The spatial subsidies approach identifies sending and receiving areas and indicates the degree to which different locations are telecoupled to one another. We thus present a first step toward identifying and quantifying telecoupled interactions that arise from migratory species and the ecosystem services that they provide to their human beneficiaries.

Responses to this article can be read online at: http://www.ecologyandsociety.org/issues/responses. $\mathrm{php} / 9589$

\section{Acknowledgments:}

We thank D. Munier, J. Pierce, and P. Ellsworth for providing information on insecticide use in cotton. This work was funded by National Science Foundation awards (DEB-1118975 and $D E B-1518359)$ to $L L H$. Additional support was received from the U.S. Geological Survey's John Wesley Powell Center for Analysis and Synthesis working group, Animal Migration and Spatial Subsidies: Establishing a Framework for Conservation Markets. LLH and KBJ thank the sTeleBes working group of the sDiv Synthesis for stimulating discussion about telecoupled ecosystem services, in particular K. Frank.

\section{LITERATURE CITED}

Bagstad, K. J., G. W. Johnson, B. Voigt, and F. Villa. 2013. Spatial dynamics of ecosystem service flows: a comprehensive approach to quantifying actual services. Ecosystem Services 4:117-125. http://dx.doi.org/10.1016/j.ecoser.2012.07.012

Bagstad, K. J., and R. Wiederholt. 2013. Tourism values for Mexican free-tailed bat viewing. Human Dimensions of Wildlife 18:307-311. http://dx.doi.org/10.1080/10871209.2013.789573 
Barbier, E. B. 2012. Progress and challenges in valuing coastal and marine ecosystem services. Review of Environmental Economics and Policy 6:1-19. http://dx.doi.org/10.1093/reep/ $\underline{\text { rer017 }}$

Brauman, K. A., G. C. Daily, T. K. E. Duarte, and H. A. Mooney. 2007. The nature and value of ecosystem services: an overview highlighting hydrologic services. Annual Review of Environment and Resources 32:67-98. http://dx.doi.org/10.1146/annurev. energy.32.031306.102758

Burkhard, B., F. Kroll, S. Nedkov, and F. Moller. 2011. Mapping ecosystem service supply, demand and budgets. Ecological Indicators 21:17-29. http://dx.doi.org/10.1016/j.ecolind.2011.06.019

Cleveland, C. J., M. Betke, P. Federico, J. D. Frank, T. G. Hallam, J. Horn, J. D. López, G. F. McCracken, R. A. Medellín, A. Moreno-Valdez, C. G. Sansone, J. K. Westbrook, and T. H. Kunz. 2006. Economic value of the pest control service provided by Brazilian free-tailed bats in south-central Texas. Frontiers in Ecology and the Environment 4:238-243. http://dx.doi. org/10.1890/1540-9295(2006)004[0238:EVOTPC]2.0.CO;2

DeFries, R. S., T. Rudel, M. Uriarte, and M. Hansen. 2010. Deforestation driven by urban population growth and agricultural trade in the twenty-first century. Nature Geoscience 3:178-181. http://dx.doi.org/10.1038/ngeo756

Eigenbrod, F., B. J. Anderson, P. R. Armsworth, A. Heinemeyer, S. F. Jackson, M. Parnell, C. D. Thomas, and K. J. Gaston. 2009. Ecosystem service benefits of contrasting conservation strategies in a human-dominated region. Proceedings of the Royal Society B: Biological Sciences 276:2903-2911. http://dx.doi.org/10.1098/ $\underline{\text { rspb.2009.0528 }}$

Eigenbrod, F., V. A. Bell, H. N. Davies, A. Heinemeyer, P. R. Armsworth, and K. J. Gaston. 2011. The impact of projected increases in urbanization on ecosystem services. Proceedings of the Royal Society B: Biological Sciences 278:3201-3208. http:// dx.doi.org/10.1098/rspb.2010.2754

Federico, P., T. G. Hallam, G. F. McCracken, S. T. Purucker, W. E. Grant, A. N. Correa-Sandoval, J. K. Westbrook, R. A. Medellín, C. J. Cleveland, C. G. Sansone, J. D. López Jr., M. Betke, A. Moreno-Valdez, and T. H. Kunz. 2008. Brazilian free-tailed bats as insect pest regulators in transgenic and conventional cotton crops. Ecological Applications 18:826-837. http://dx.doi. org/10.1890/07-0556.1

Genoways, H. H., P. W. Freeman, and C. Grell. 2000. Extralimital records of the Mexican free-tailed bat (Tadarida brasiliensis mexicana) in the central United States and their biological significance. Transactions of the Nebraska Academy of Sciences 26:85-96.

Gilbert, L. E. 1980. Food web organization and the conservation of neotropical diversity. Pages 11-34 in M. E. Soule and B. A. Wilcox, editors. Conservation biology: an evolutionary-ecological perspective. Sinauer Associates.

Glass, B. P. 1982. Seasonal movements of Mexican freetail bats Tadarida brasiliensis mexicana banded in the Great Plains. Southwestern Naturalist 27:127-133. http://dx.doi.org/10.2307/3671136
Hulina, J., C. Bocetti, H. Campa III, V. Hull, W. Yang, and J. Liu. 2017. Telecoupling framework for research on migratory species in the Anthropocene. Elementa Science of the Anthropocene 5:5. http://dx.doi.org/10.1525/elementa.184

Johnson, K. A., S. Polasky, E. Nelson, and D. Pennington. 2012. Uncertainty in ecosystem services valuation and implications for assessing land use tradeoffs: an agricultural case study in the Minnesota River Basin. Ecological Economics 79:71-79. http:// dx.doi.org/10.1016/j.ecolecon.2012.04.020

Kastner, T., K.-H. Erb, and H. Haberl. 2014. Rapid growth in agricultural trade: effects on global area efficiency and the role of management. Environmental Research Letters 9:034015. http://dx. doi.org/10.1088/1748-9326/9/3/034015

Kastner, T., K.-H. Erb, and S. Nonhebel. 2011. International wood trade and forest change: a global analysis. Global Environmental Change 21:947-956. http://dx.doi.org/10.1016/j. gloenvcha.2011.05.003

Keeley, B. W., M. B. Fenton, and E. Arnett. 2003. A North American partnership for advancing research, education, and management for the conservation of bats and their habitats. Wildlife Society Bulletin 31:80-86.

Kissinger, M., and W. E. Rees. 2010. Importing terrestrial biocapacity: the U.S. case and global implications. Land Use Policy 27:589-599. http://dx.doi.org/10.1016/j.landusepol.2009.07.014

Kissinger, M., W. E. Rees, and V. Timmer. 2011. Interregional sustainability: governance and policy in an ecologically interdependent world. Environmental Science \& Policy 14:965976. http://dx.doi.org/10.1016/j.envsci.2011.05.007

Koch, E. W., E. B. Barbier, B. R. Silliman, D. J. Reed, G. M. E. Perillo, S. D. Hacker, E. F. Granek, J. H. Primavera, N. Muthiga, S. Polasky, B. S. Halpern, C. J. Kennedy, C. V. Kappel, and E. Wolanski. 2009. Non-linearity in ecosystem services: temporal and spatial variability in coastal protection. Frontiers in Ecology and the Environment 7:29-37. http://dx.doi.org/10.1890/080126

Kunz, T. H., E. B. de Torrez, D. Bauer, T. Lobova, and T. H. Fleming. 2011. Ecosystem services provided by bats. Annals of the New York Academy of Sciences 1223:1-38. http://dx.doi. org/10.1111/j.1749-6632.2011.06004.X

Lautenbach, S., R. Seppelt, J. Liebscher, and C. F. Dormann. 2012. Spatial and temporal trends of global pollination benefit. PLoS One 7:e35954. http://dx.doi.org/10.1371/journal.pone.0035954

Leach, A. W., and J. D. Mumford. 2008. Pesticide environmental accounting: a method for assessing the external costs of individual pesticide applications. Environmental Pollution 151:139-147. http://dx.doi.org/10.1016/j.envpol.2007.02.019

Lee, Y.-F., and G. F. McCracken. 2005. Dietary variation of Brazilian free-tailed bats links to migratory populations of pest insects. Journal of Mammalogy 86:67-76. http://dx.doi. org/10.1644/1545-1542(2005)086<0067:DVOBFB $>2.0$. CO;2

Lenzen, M., D. Moran, K. Kanemoto, B. Foran, L. Lobefaro, and A. Geschke. 2012. International trade drives biodiversity threats in developing nations. Nature 486:109-112. http://dx.doi. org/10.1038/nature 11145 
Liu, J., V. Hull, M. Batistella, R. DeFries, T. Dietz, F. Fu, T. W. Hertel, R. C. Izaurralde, E. F. Lambin, S. Li, L. A. Martinelli, W. J. McConnell, E. F. Moran, R. Naylor, Z. Ouyang, K. R. Polenske, A. Reenberg, G. de Miranda Rocha, C. S. Simmons, P. H. Verburg, P. M. Vitousek, F. Zhang, and C. Zhu. 2013. Framing sustainability in a telecoupled world. Ecology and Society 18 (2):26. http://dx.doi.org/10.5751/ES-05873-180226

Liu, J., W. Yang, and S. Li. 2016. Framing ecosystem services in the telecoupled Anthropocene. Frontiers in Ecology and the Environment 14:27-36. http://dx.doi.org/10.1002/16-0188.1

López-Hoffman, L., C. C. Chester, D. J. Semmens, W. E. Thogmartin, M. S. Rodríguez-McGoffin, R. Merideth, and J. E. Diffendorfer. 2017. Ecosystem services from transborder migratory species: implications for conservation governance. Annual Review of Environment and Resources 42.

López-Hoffman, L., E. D. McGovern, and K. W. Flessa. 2009. Conservation of shared environments: learning from the United States and Mexico. University of Arizona Press.

López-Hoffman, L., D. Semmens, and J. Diffendorfer. 2013. How do migratory species add ecosystem service value to wilderness? International Journal of Wilderness 19:14-19.

López-Hoffman, L., R. G. Varady, K. W. Flessa, and P. Balvanera. 2010. Ecosystem services across borders: a framework for transboundary conservation policy. Frontiers in Ecology and the Environment 8:84-91. http://dx.doi.org/10.1890/070216

López-Hoffman, L., R. Wiederholt, C. Sansone, K. Bagstad, P. Cryan, J. Diffendorfer, J. Goldstein, K. LaSharr, J. Loomis, G. McCracken, A. Russell, and D. Semmens. 2014. Market forces and technological substitutes cause fluctuations in the value of bat pest-control services for cotton. PLoS One 9:e87912. http:// dx.doi.org/10.1371/journal.pone.0087912

Lundberg, J., and F. Moberg. 2003. Mobile link organisms and ecosystem functioning: implications for ecosystem resilience and management. Ecosystems 6:87-98. http://dx.doi.org/10.1007/ $\underline{\text { s10021-002-0150-4 }}$

McCracken, G. F. 2003. Estimates of population sizes in summer colonies in Brazilian free-tailed bats (Tadarida brasiliensis). Pages 127-237 in T. J. O. S. A. M. A. Bogan, editor. Monitoring trends in bat populations of the United States and territories: problems and prospects. U.S. Geological Survey, Reston, Virginia, USA.

McCracken, G. F., J. K. Westbrook, V. A. Brown, M. Eldridge, P. Federico, and T. H. Kunz. 2012. Bats track and exploit changes in insect pest populations. PLoS One 7:1-10. http://dx.doi. org/10.1371/journal.pone.0043839

Medellin, R. A. 2003. Diversity and conservation of bats in Mexico: Research priorities, strategies, and actions. Wildlife Society Bulletin 31:87-97.

Muradian, R., and L. Rival. 2012. Between markets and hierarchies: the challenge of governing ecosystem services. Ecosystem Services 1:93-110. http://dx.doi.org/10.1016/j. ecoser.2012.07.009

Peterson, M. J., D. M. Hal, A. M. Feldpausch-Parker, and T. R. Peterson. 2010. Obscuring ecosystem function with application of the ecosystem services concept. Conservation Biology 24:113119. http://dx.doi.org/10.1111/j.1523-1739.2009.01305.x

Rayfield, B., M.-J. Fortin, and A. Fall. 2011. Connectivity for conservation: a framework to classify network measures. Ecology 92:847-858. http://dx.doi.org/10.1890/09-2190.1

Robbins, P. 2011. Political ecology: a critical introduction. John Wiley \& Sons.

Semmens, D. J., J. E. Diffendorfer, L. López-Hoffman, and C. D. Shapiro. 2011. Accounting for the ecosystem services of migratory species: quantifying migration support and spatial subsidies. Ecological Economics 70:2236-2242. http://dx.doi. org/10.1016/j.ecolecon.2011.07.002

Spash, C. L. 2008. How much is that ecosystem in the window? The one with the bio-diverse trail. Environmental Values 17:259284. http://dx.doi.org/10.3197/096327108X303882

Taylor, C. M., and D. R. Norris. 2010. Population dynamics in migratory networks. Theoretical Ecology 3:65-73. http://dx.doi. org/10.1007/s12080-009-0054-4

Wenny, D. G., T. L. Devault, M. D. Johnson, D. Kelly, C. H. Sekercioglu, D. F. Tomback, and C. J. Whelan. 2011. The need to quantify ecosystem services provided by birds. Auk 128:1-14. http://dx.doi.org/10.1525/auk.2011.10248

Wiederholt, R., L. Lopez-Hoffman, J. Cline, R. A. Medellin, P. Cryan, A. Russell, G. McCracken, J. Diffendorfer, and D. Semmens. 2013. Moving across the border: modeling migratory bat populations. Ecosphere 4:1-16. http://dx.doi.org/10.1890/ ES13-00023.1

Wiederholt, R., L. Lopez-Hoffman, C. Svancara, G. McCracken, W. Thogmartin, J. E. Diffendorfer, B. Mattsson, K. Bagstad, P. Cryan, A. Russell, D. Semmens, and R. A. Medellin. 2015. Optimizing conservation strategies for Mexican free-tailed bats: a population viability and ecosystem services approach. Biodiversity and Conservation 24:63-82. http://dx.doi.org/10.1007/ s10531-014-0790-7

Yuan, Y., J. T. Liu, H. T. Liu, L. M. Tan, and H. J. Liu. 2012. Spatial-temporal variation of ecosystem services in response to land use changes: Case study in the 38 degrees $\mathrm{N}$ ecological transect of Northern China. Journal of Food Agriculture \& Environment 10:794-802. 